\title{
What Contributes to the Progression of Rheumatoid Arthritis?
}

\author{
Article by Abdirahman Hassan \\ PhD, Texila American University \\ E-mail: awale_hassan@hotmail.com
}

\begin{abstract}
Rheumatoid Arthritis is an autoimmune disorder and it is the most common autoimmune and inflammatory arthritis in adults (Helmic, et al, 2008), the disease mainly affects joints of the body such as knees, hands and hips. The ideology of this inflammation is unknown (Fishman, 2010). However, there are several factors that mainly contribute to the initiation and the progression of the Rheumatoid Arthritis this include gender, age, environmental factors, malnutrition and genetic makeups. The disease occurs approximately $1 \%$ of the population. It is more common in women than the male; about $80 \%$ of the cases are seen on the population between the ages of 35-50 year (Fishma, 2010). The management intervention of this disease must be started sooner rather than later, the treatment should be widely comprehensive including pain management, reducing swelling and supporting the patients to receive proper treatment that aims to cure the disease and the condition. Radiographic image should be taken to evaluate the extent of the damages on joints. This study investigates the factors that contribute the progression of the Rheumatoid Arthritis.
\end{abstract}

Keywords: Rheumatoid Arthritis, Autoimmune disorder, inflammatory arthritis.

\section{Introduction}

Definition: Rheumatoid Arthritis (RA) can be defined as an autoimmune disease in which the body immune system mistakenly attacks itself and this autoimmune disease particularly targets synovial tissues, cartilage and bone and causes inflammation and stiffness in the joints and the tissues around. If the symptoms are persistent without intervention, the joint will get damaged and this will lead patients to disability if immediate treatment was not introduced, the most important symptoms for immune medicated arthritis are joint pain, swelling, heat and redness. It is obvious that rheumatoid Arthritis results abnormal inflammation to the joints but this not limited to joints and there are other parts and organs in the body that RA can have negative impact on it such as eyes, lungs and blood vessels and therefore the symptoms and signs varies and patients can show the following signs and symptoms such as loss of energy, low grade fever, weight loss and anaemia. The other signs that some patients showed can be rheumatoid nodule where lamp can be seen under the skin, this tumour is not cancerous.

In Rheumatoid Arthritis, there is no single sign or pattern of signs and symptoms that we can use as a measurement to diagnose this disease, the symptoms may varies in their nature and for some people severe and clear symptoms can be seen on particular time but on some occasions less obvious symptom presented by the patients. Likewise, some patients present symptoms on one joint on a time and bilateral on the other times and it is widely accepted by clinicians that, Rheumatoid Arthritis patients presents symptoms of being sick and tired and they might frequently show a degree of low grades of fever, as mentioned above mainly RA patients consider this disease chronic and they expect that its treatment will last longer and continues for life and therefore prolonged presence of RA will cause more damage to the joints and eventually this will lead to complete disability and deformation to the effected bones. 


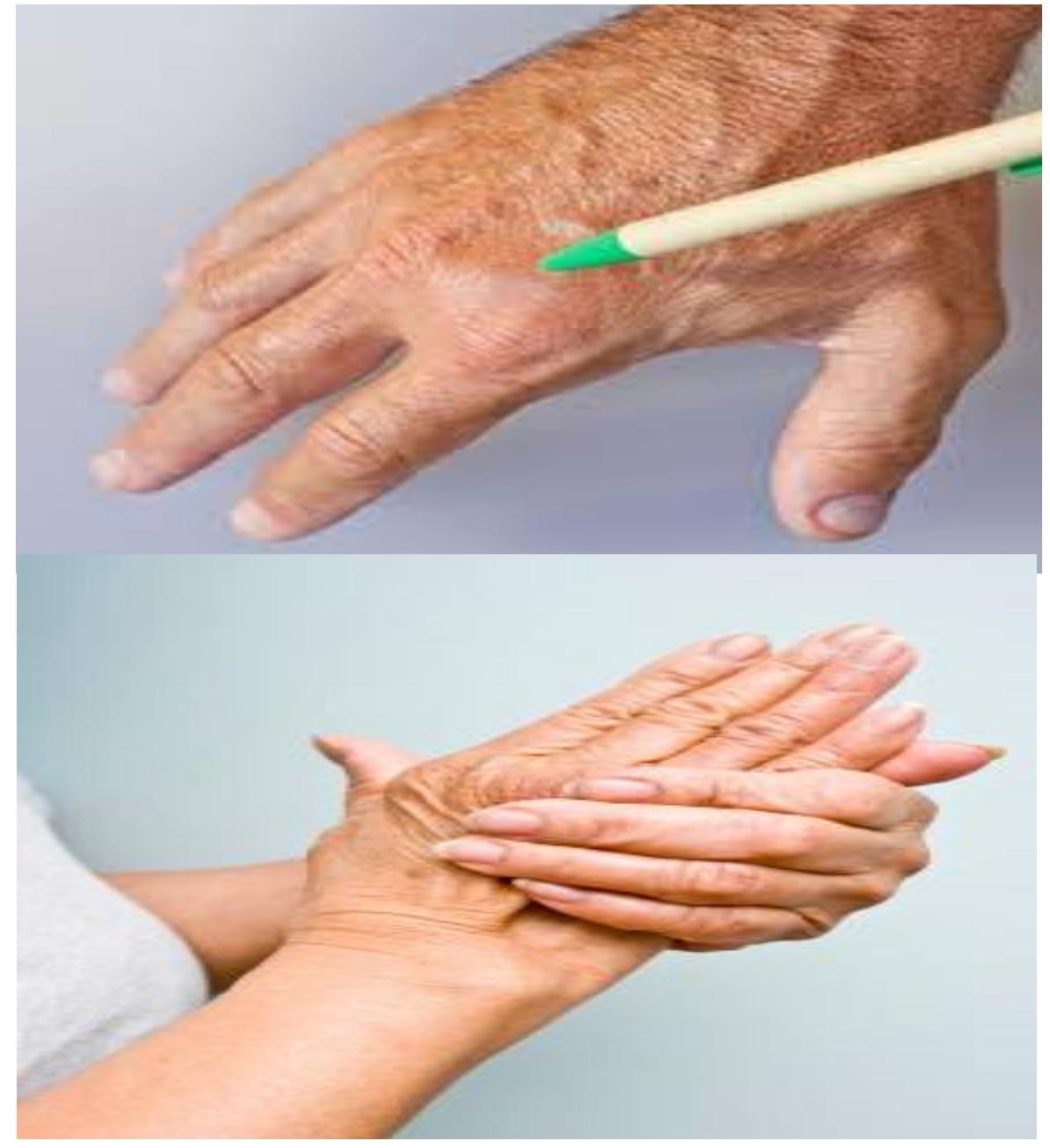

Figure 1. These figures show the early stages of bone deformation in RA patient

\section{Rheumatoid arthritis epidemiology}

Epidemiologically, Rheumatoid Arthritis affects $1 \%$ of the population in general. However, Canadian people who affected by RA is about $16 \%$ of total population, approximately 4.2 million Canadians aged 15 or older are mainly current suffering RA (Figure. 1a). 


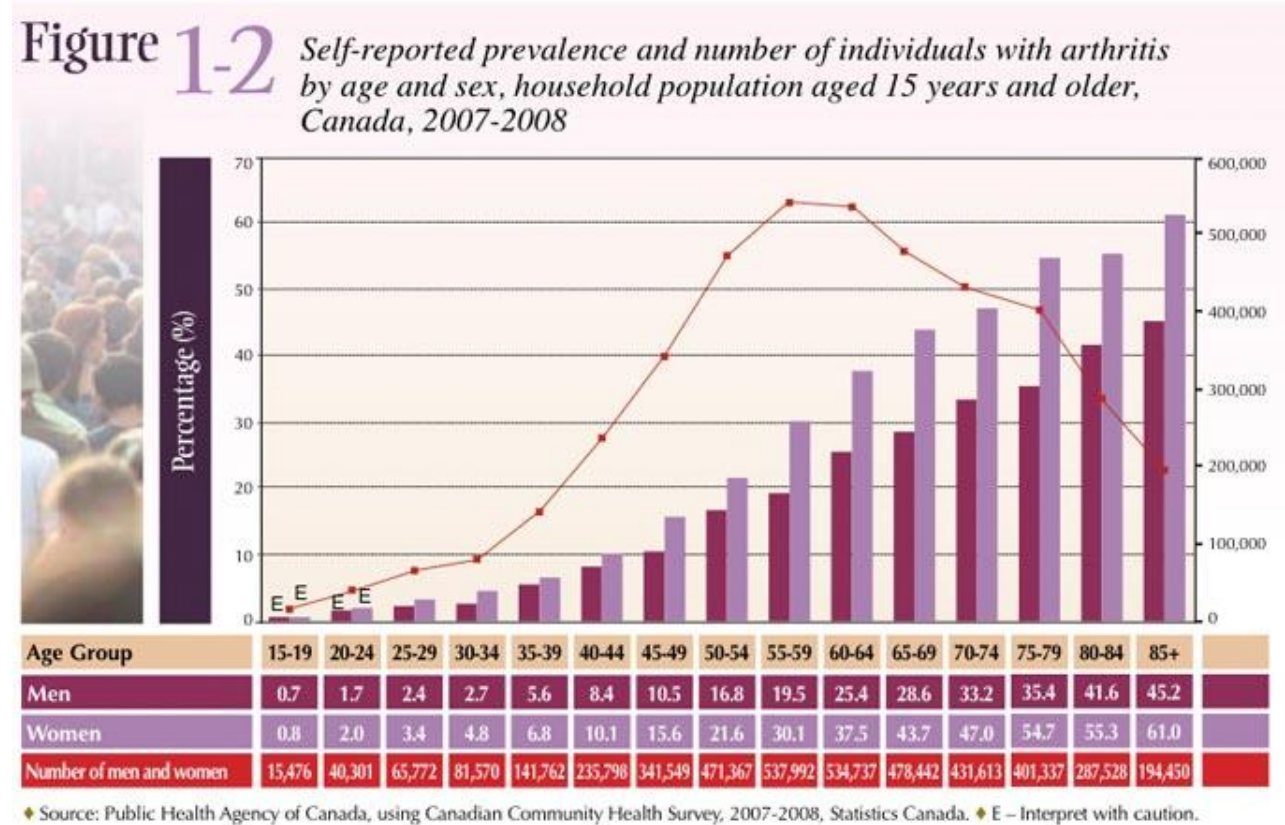

Figure 1a. Prevalence of rheumotoid arthritis in canadian populations

\section{What causes rheumatoid arthritis?}

Rheumatoid Arthritis is an autoimmune disease in which no known aetiology and causes have been identified. However, there are several factors that mainly contribute to the initiation and the progression of the Rheumatoid Arthritis this includes gender, age, environmental factors, malnutrition and genetic makeups and maybe other factors as previously stated.

\section{Test and diagnosis}

Patients with RA usually present with chief complain of pain and stiffness in many joints. The wrists, proximal interphalangeal joints, and metacarpophalangeal joints are main the parts of body where inflammation take place. Stiffness is severer in the morning and it might last for several hours. Clear swelling due to synovitis can be obvious and visible (Figure, 2and2a). During the medical examination synovial thickening is observable and also palpable on joint examination. Joint discomfort or arthralgia is common sign that patients present before the onset of clinically apparent joint swelling. Further sign and symptoms of weight loss, and low-grade fever, and fatigue may occur with active disease.

An attempt to create guideline to recognise the early symptoms to begin early intervention joint committee from the American College of Rheumatology and European League against Rheumatism collaborated to create new classification criteria for RA.

The aim of the new criteria are facilitation to diagnose RA earlier in patients who may not meet the 1987 American College of Rheumatology classification criteria and this joint criteria are formulated in 2010. These criteria will not involve or not included presence of rheumatoid nodules or radiographic erosive changes, because both of them are not present in early stage of RA.

\section{The role of autoantibody}

The presence of autoantibody is characterised as a presence of autoimmune disease but presence of rheumatoid factor is not represent the presence of autoimmune disease, but RF is one of the test ordered by the physician yet it not definitive answer for autoimmune disease since many other condition and disease can show high level of RF therefore Rheumatoid factor is not specific for RA and may be present in patients with other diseases, such as hepatitis $\mathrm{C}$, and in healthy older persons.

As Szekanecz et al have stated that Anti-citrullinated protein antibody (ACPAs) was discovered as new serological marker for rheumatoid arthritis and (ACPAs) has grater sensitive and specificity and these characteristics plays important role in disease pathogenesis. Regarding molecular biology level and protein level in diagnostic laboratories and about $80 \%$ of rheumatoid arthritis patients are either 
positive in Rheumatoid factor or ACPAs or both. Anti-perinuclear Factor (APF) and anti-keratin antibodies are the first autoantibody family that recognise citrullinated epitopes of filaggrin.

In diagnostic process the presence and the absent of citrullinated proteins rheumatoid arthritis is important, discovery of citrullinated epitops used as target for anti-filaggrin antibody facilitated the existence of generations of anti-citrullinated peptide antibody assays. Similarly, anti-CCP2 assays possess high diagnostic sensitivity and specificity, and they also show important predictive and prognostic value in RA (Synoms Et., al 2000).

Although, anti-Sa antibody was been identified many year ago, new scientific studies suggested that anti-Sa is linked to citrullinated vimentin, and therefore it is recognised as a member of the family of ACPAs. Likewise recently identified anti-mutated citrullinated vimentin (anti-MCV) assay showed the similar diagnostic performance with anti-CCP2 ELISA. In diagnostic process the combination of anti$\mathrm{CCP} 2$ and anti-MCV assays showed high certainty to laboratory diagnostics of RA. It is clearly certain that ACPA family needs to expand and there are room for improvement to develop new strategies for RA diagnostics and treatment including designing and developing new cutting-age bioassays.

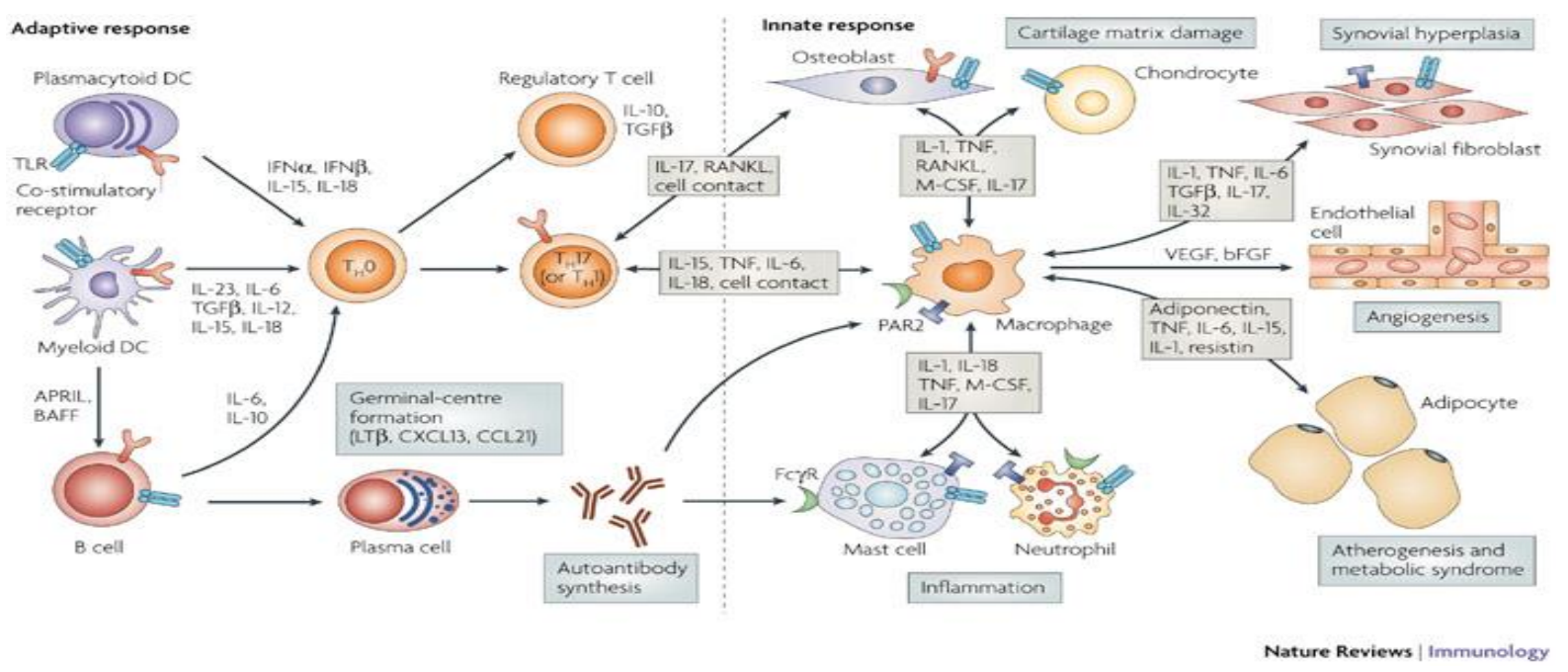

Figure 3. Shows events take place in both Innate and Adaptive immune system and the process of antibody antigen interaction with inflammation process

To investigates the patient with suspected RA, physicians and medical team such as biomedical scientist need to perform series of tests, such as nuclear antibody test, particularly in juvenile forms of the disease. Other tests are of equal importance are CRP and ESR as they are the indicative methods for increase of RA, the level of theses test can used as a marker of activity and response to medication. Because RA is systemic disease that can affect any part of the body and it's not affecting only joints, bones and muscles the investigation process needs to be well crafted and carefully planned process. Joint aspirations known as Arthrocentesis is done, where sterile syringe and needle is directly taken fluid from joints mainly knees and hand joins for double benefits, one being elevation of pain and the fluid to be analysed for further investigation. However, in some case a dose of cortisone is injected into effected joints by trained professions to reduce pain.

Normally after initial test is completed such as blood tests other diagnostic equipment are employed. Taking radiographic images of hands and feet should be performed to evaluate for characteristic of the bone damage. An X-rays is useful in the latter stage of RA and it can clearly show bone erosion and for further investigation and evaluation of the extant of the damage bone density scans, ultrasound and magnetic resonance imaging must be used. 


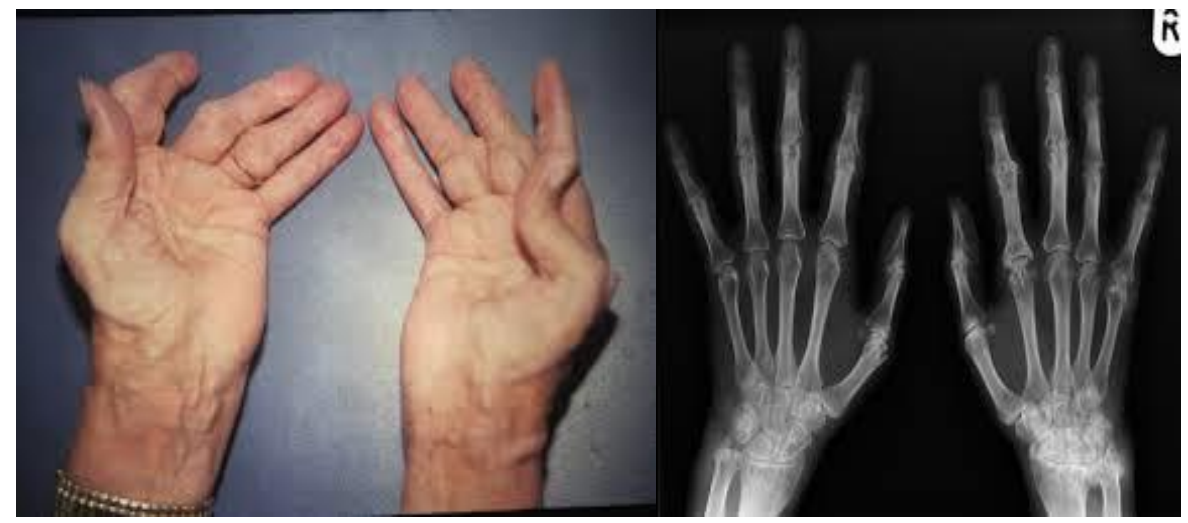

Figure 3a $\boldsymbol{\&}$ 3b. Shows the image of X-ray taken from RA patient.

Diagnostic procedure must be continues such as complete blood count (CBC) with differential, liver functions test (LFT) and renal function test (RFT) to avoid treatment that cause further damage to the patients with liver and kidney problems, this medication can include but not limited to non-steroid antiinflammatory drugs (NSAID).

\section{Treatment}

The role of treatment comes after diagnosis procedure of Rheumatoid Arthritis is completed and the type of treatment and procedure must be agreeable between medical team and patient and the negatives and positives should be discussed including duration of the regimen, positive outcomes and drug side effects. Female patient must be given extra care and possible pregnancy must be ruled out. The main objectives of the treatment must not be intended the elevation of pain only. However, pain management, reducing swelling and preventing deformity is fundamental stages for effective RA treatment. The treatment should be comprehensive including pain management, reducing swelling and supporting the patients to receive proper treatment that aims to cure the disease of the conditions, radiographic image should be taken to evaluate the extent of the damages on joints.

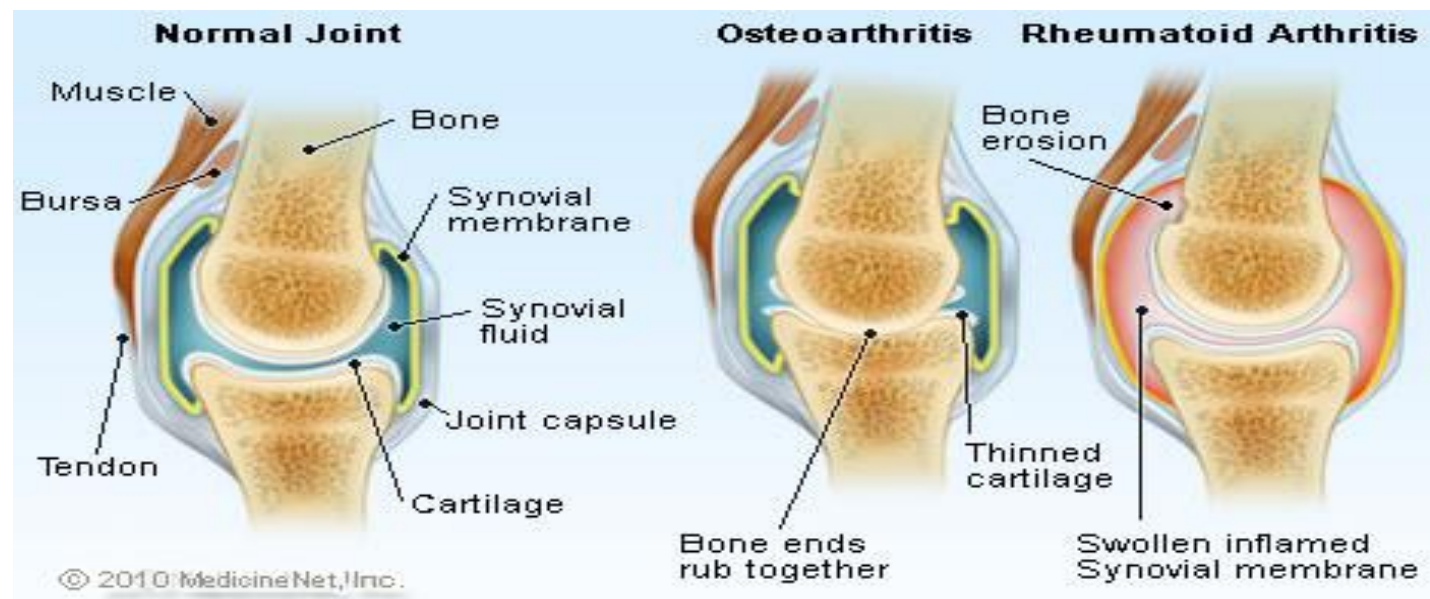

\section{Normal and Arthritic Joints}

Figure 4. The figure shows the difference between normal join, Osteoarthritis and Rheumatoid Arthritis

A group of drugs that are used to treat Rheumatoid Arthritis are the important medication available and this drug called Disease-modifying antirheumatic drugs (DMARDS) This drug helps patients with rheumatoid arthritis. Their main object is to decrease pain and inflammation. However, they are not painkiller but they change the underlying disease, rather than treating the symptoms. The reduction of the swelling and managing pain will slows down the progression of the disease and thus prevents joint damage. This drug can be divided into biologic and non-biologic, or biological and conventional nomonclonal antibodies and recombinant receptors that block cytokines and promote the inflammatory 
DOI: 10.21522/TIJCR.2014.04.02.Art008

ISSN: 2520-3096

cascade that causes the symptoms of the Rheumatoid Arthritis are the examples of biologic DMARDs drug.

Table.1. the above table shows the approved biological DMARDs and related drugs in development

\begin{tabular}{|c|c|c|c|}
\hline Agent & Status ${ }^{\ddagger}$ & Properties & Comments \\
\hline \multicolumn{4}{|c|}{ Anti-TNF therapies } \\
\hline Infliximab & $\begin{array}{l}\text { Approved } \\
\text { (RA: 1999) }\end{array}$ & $\begin{array}{l}\text { Chimaeric monocional antibody } \\
\text { to TNF }\end{array}$ & $\begin{array}{l}\text { First biological DMARD to be clinically } \\
\text { tested; trials showed that TNF blockade is } \\
\text { clinically effective short- and bng-term }\end{array}$ \\
\hline Etanercept & $\begin{array}{l}\text { Approved } \\
\text { (1998) }\end{array}$ & $\begin{array}{l}\text { Construct of TNF-RIl and the FC } \\
\text { portion of IgG1 }\end{array}$ & $\begin{array}{l}\text { Efficacy in RA comparable to infliximab used } \\
\text { as a monotherapy or combination therapy }\end{array}$ \\
\hline Adalimumab & $\begin{array}{l}\text { Approved } \\
(2002)\end{array}$ & Human monocional antibody to TNF & $\begin{array}{l}\text { Efficacy in RA comparable to infliximab used } \\
\text { as a monotherapy or combination therapy }\end{array}$ \\
\hline CDP870 & In study & $\begin{array}{l}\text { PEGylated Fab fragment of CDP571, } \\
\text { a humanized antibody to TNF }\end{array}$ & \\
\hline PEG-TNF-RI & In study & PEGylated form of soluble TNF-RI & \\
\hline \multicolumn{4}{|c|}{ IL-1-blocking agents } \\
\hline Anakinra & $\begin{array}{l}\text { Approved } \\
\text { (2001) }\end{array}$ & IL-1R antagonist & $\begin{array}{l}\text { Clinically effective as a monotherapy and in } \\
\text { combination with MTX }\end{array}$ \\
\hline IL-1 trap & Phase I & $\begin{array}{l}\text { Construct of two IL-1R chains with } \\
\text { an IgG-Fc domain }\end{array}$ & \\
\hline
\end{tabular}

See ONLINE TABLE 2 for a more detailed version, induding adverse events. IYears shown are those of the first approvals in a major phamaceutical market. Anti-TNF therapies are descabed in REFS61,80-91; IL-1-blocking agents are described in REFS 92-96. DMARD, disease-modiying anti-heumatic drug; IgG1, immunogobuin G1; IL-1, interleukin-1; IL-1R, interleukin-1 receptor; MTX, methotrexate; RA, houmatcid arthritis; TNF, tumaur-necrosis tactor; TNF-R, tumou-necrosis factor receptor.

The effect of these drugs might not been seen quickly and it usually takes several weeks to work for the patients. Although, there are number of DMARDs that are used for treatment of RA, it is important to mention one of these important drugs Methotrexate can be an excellent example. Methotrexate is the most frequently used drug for the treatment of the RA, and it has been on the market for decades and it's the first-line prescription in patients with active rheumatoid arthritis, most the patients tolerates but there are number of side effects. Leflunomide is considered as the alternative to methotrexate but it has more gastrointestinal side-effects, similarly hydroxychloroquine is will elicit good affect when used as a mono-therapy, however, synergic drugs are more effective than mono-therapy but in most cases the combined drugs might show greater adverse effects. Tumour necrosis factor inhibitors (TNFi) belong to the group of biologic drugs that are the most studied and the first-line of biological therapy. 
Table 2. Small-molecule DMARDs in clinical use

\begin{tabular}{|c|c|c|}
\hline Agent & First used & Comments \\
\hline Gold salts & $1920 \mathrm{~s}$ & $\begin{array}{l}\text { Relatively long period of administration before } \\
\text { clinical effects are seen; rarely used today }\end{array}$ \\
\hline Sulphasalazine & $1940 \mathrm{~s}$ & $\begin{array}{l}\text { Second most common DMARD used in Eurcpe } \\
\text { during the } 1990 \mathrm{~s}\end{array}$ \\
\hline Antimalarials & $1960 \mathrm{~s}$ & $\begin{array}{l}\text { Less efficacious than other DMARDs, but also } \\
\text { less toxic }\end{array}$ \\
\hline Methotrexate & $1960 \mathrm{~s}$ & Gold-standard therapy \\
\hline o-penicillamine & $1960 \mathrm{~s}$ & One of the more toxic DMARDs; rarely used today \\
\hline $\begin{array}{l}\text { Azathioprine, } \\
\text { myccophendic acid }\end{array}$ & $1960 \mathrm{~s}$ & Some clinical benefit \\
\hline $\begin{array}{l}\text { Cyclosporine } A \\
\text { tacrolimus, sirolmus }\end{array}$ & $1980 \mathrm{~s}$ & $\begin{array}{l}\text { Efficacious, but relative toxicity has precluded } \\
\text { widespread use }\end{array}$ \\
\hline Minocycline & $1990 \mathrm{~s}$ & Mildly beneficial \\
\hline Leflunomide & $1990 \mathrm{~s}$ & $\begin{array}{l}\text { Overall, has similar effects to sulphasalazine } \\
\text { and methotrexate }\end{array}$ \\
\hline Glucocorticoids & $1960 \mathrm{~s}$ & $\begin{array}{l}\text { Rapid anti-inflammatory effects, but also qualities } \\
\text { of DMARDs; however, have long-term side effects }\end{array}$ \\
\hline
\end{tabular}

"See ONLINE TABLE 1 for a more detailed referenoad version. "Chloroquine, hydroxychloroquine. DMARD, disease-modfying antiriteumatic drug.

Prescribing such medication to patients who are suffering a significant thrombocytopenia and those with renal failure must be evaluated by specialist in this field and benefit must outweighs the damage and safety of the patients must not be compromised. Several considerable studies concluded that the administration of the Methotrexate drug contraindicated in patients with hepatic disease, particularly hepatitis $\mathrm{C}$, and those with significant renal impairment. Before using TNF inhibitor, as a biological therapy, tuberculin test must be performed to rule out TB. As reported by (ref) use of TNF inhibitor reactivates Hepatitis B.

\section{NSAIDS and corticosteroids}

The process and steps of treating the RA usually involves administrations of NSAIDs using the corticosteroids for controlling pain and inflammation. Using these medications should be in a short time and should not be used for long period.

\section{Complementary therapies}

There are very controversial idea that says malnutrition and the kind of food consumed can greatly contributes the RA, on the other hand there is another opinion supporting that some sort of mutations can passively decrease the effect RA and can be used as medication this maturation including vegetarian and Mediterranean diets. 
DOI: $10.21522 / \mathrm{TIJCR} .2014 .04 .02 . A r t 008$

ISSN: $2520-3096$

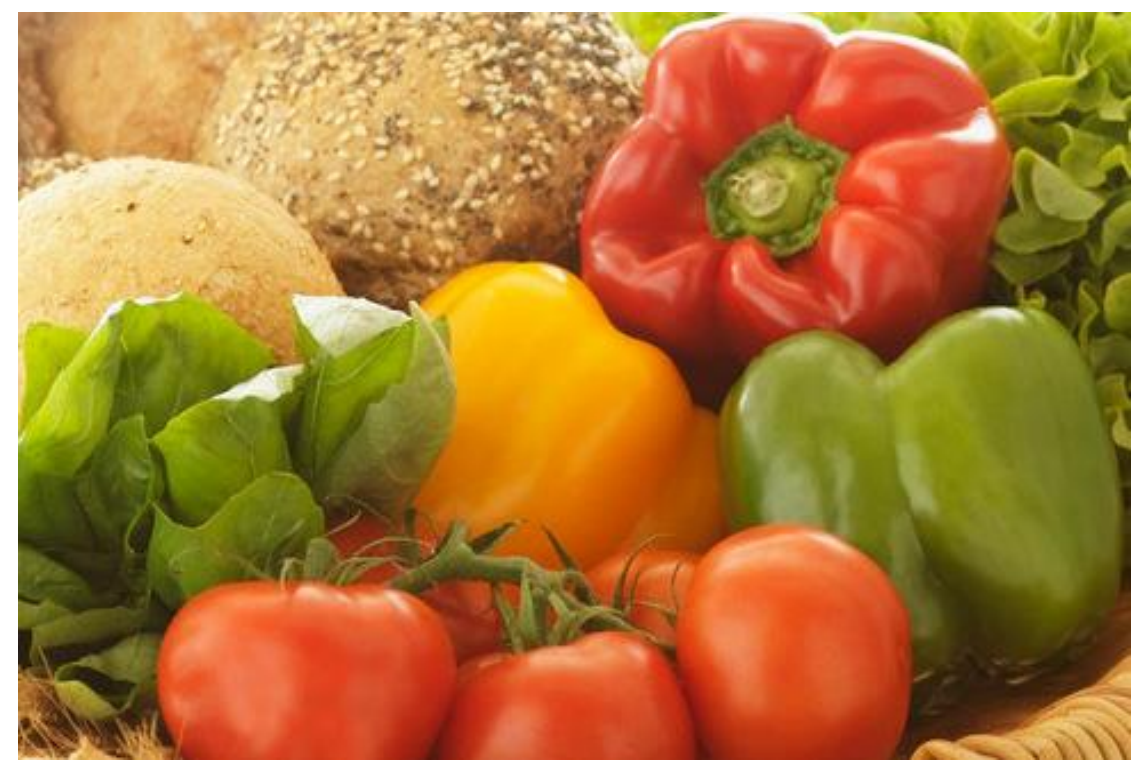

Figure 5. This figure shows the sample of the food that RA patients need to consume to reduce the RA inflammation.

However, there is no enough evidence to support neither of the claims. Similarly, other unconfirmed studies indicate that acupuncture therapy helps and reduce tendency and pain in joints. 


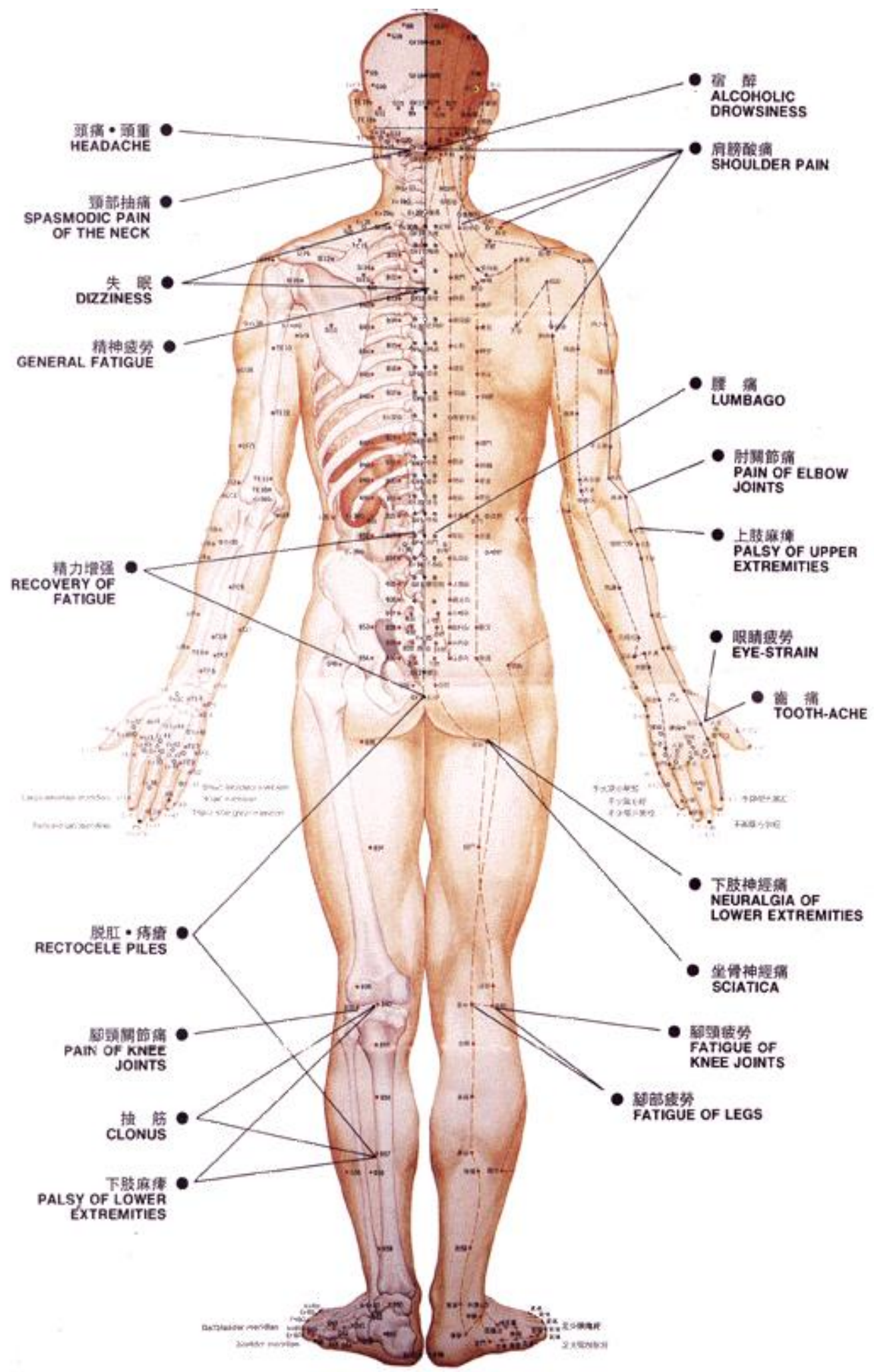

Figure 5a. Shows the targeted joints to elevate agony from the body

Several studies show that smoking is genuine factor that increases the progression of the RA and physician must advice patients to quit or at least minimising the quantity of cigarettes they consume per day, as this reduction can contribute and causes to slow the progression of the disease and enhance the quality of human life. 


\section{Exercise and physical therapy}

Various studies show that moderate and regular exercise positively contributes the reduction of inflammation and thus improves the quality of life of Rheumatoid Arthritis patients. However, there is no evidence based results that concludes concrete relationship between the exercise and complete relief of the disease. Prescribing regular physical exercise has not been adopted yet. RA treatment is not timely respond medication and this might depend on the patient's attitude, the mechanism of the treatment and drug intervention regimen chosen and the duration of the treatment.

The main object of management of RA in early disease is to reduce disease activity, to prevent loss of function, and to control joint damage. It is important to know that this procedure requires adequate time to achieve an expected outcome and through process with enough duration of time can be achieved positive results and the control for further damage to the bones and joints that were affected by RA.

\section{Joint replacement}

The option of joint replacement for Rheumatoid Arthritis patients comes after the control of disease progression, and other treatments are not showing satisfactory results or when there is structural damage to a joint or the tissues around it. There are several types of joint surgeries including total joint replacement. However, the most common ones are hip replacement, knee replacement, shoulder replacement and finger replacement. The orthopaedic surgeon will evaluate the damage and they should be satisfied that the joint replacement will be best option for the patients and this be bring pain relief and therefore movement will improved.

\section{Discussion and conclusion}

Rheumatoid Arthritis is an autoimmune disease that affects all joints particularly hips, knees hands and fingers(Figures 1, 1a, 1b) Public health practitioners in both UK and US stated that approximately $1 \%$ of adult population of United Kingdom and United States of America has this chronic disease (Luqmani, 2009). Over the past decades, Rheumatoid Arthritis affected negatively the life of many people around the world, and this hugely contributed the increase of disability of millions of people, resulting spending billions of pounds to support RA victims around the globe. However, these financial supports have greatly improved their socio-economic burden caused by this disease. Researchers have tried to invent and discover effective medicine, surgery and devices to support patients, in order to achieve acceptable outcomes.

To critically evaluate the scientific research done by experts of the field, did not achieve acceptable results. A number of research studies have suggested various types of interventions but again this intervention did not yield tangible results and the reason being, the approach was not well formulated and therefore, unnecessary time, effort, and financial means were spent unwisely. The study of the mechanism of autoimmune disease took many years as well, yet the exact biological mechanism is not fully understood. Pain management is very crucial but temporary pain relief without disturbing the resources of the inflammation is just tedious work without expectation of fruitful result. Failure to achieve acceptable outcomes is merely wasting time and resources. The aim and the object of any study that attempting discovery and development of new medication, device or surgery for RA is not only to halt and manage the pain temporarily. The least investigated approach to improve the well-being of the RA patients is prevention strategy, as said before, prevention is better than the treatment. Genetic predisposition is a valid factor, however, environment and food and lack of exercises also plays an important role in the prevalence of Rheumatoid Arthritis. The molecular understanding of RA is important for seeking answers of questions regarding the mechanisms of inflammatory responses, mechanisms of tissue destruction, genetic analysis and the effect of food consumed and malnutrition in general. Although some scientists arguing that there is a lot to be done about understanding of molecular mechanisms. On the other hand, there are well established immunologist who arguably stated that scientific development have achieved enough understanding of the mechanisms of cell communication and the regulation of immune responses, not only that but also the mechanism cell mediated immune responses and tissue injury, and the process of injury and cell damage. (Smith, 2002) concludes that the knowledge of cell process and communication is very satisfying and therefore effective treatment has been developed. In fact, the newer treatments represent the "tip of the iceberg," says (Smith 2002). 
Nevertheless, this scientific hypothesis is eventually an opinion that is not widely welcomed by the wide range of the scientific society, particularly immunologists and therefore, there is a lot to be done. The distance to the destination to reach conclusion is very far and rigorous research and development is important to celebrate the achievement of RA been eradicated or cured. Despite intensive research, the cause of this autoimmune disorder is mysterious. And for this reason the cells or gene factor that is responsible for the progression of RA is also remains elusive. However, several studies suggested that white blood cell specially macrophages plays particular important role in progression of the RA, we cannot rule out the vital roles that other inflammatory cells in the progression of this disorder (Fishman, 2010). As Fisher stated in the Synovium, macrophages are well able to present antigen and to activate T-cells and furthermore the infiltration of the macrophage in to the synovium will reflect with severity and the progression of the RA (Maruotti et al. 2007). Fisherman concluded that "Macrophage-derived cytokines, such as tumours necrosis factor alpha (TNF-a), appear to play a critically important role in the induction and perpetuation of the chronic inflammatory processes in rheumatoid joints as well as in the systemic manifestations of this disease" (Grossman and Brahn 1997).

\section{References}

[1].Abdel-Nasser A. M, Rasker JJ, Valkenburg HA. Epidemiological and clinical aspects relating to the variability of rheumatoid arthritis. Seminars in Arthritis \& Rheumatism 1997; 27(2):123-140.

[2].American Society for Surgery of the Hand www.handcare.org accessed on 20, 24 and 25, of May, 2016.

[3].Arnett FC, Edworthy SM, Bloch DA et al. Revised criteria for the classification of rheumatoid arthritis. Arthr Rheum 1988; 31: 315-24.

[4].Department of Health and Social Security, Morbidity statistics from general practice 1971-2. Second national morbidity study London: HMSO, 1979.

[5].De Jong Z, Munneke M, Zwinderman AH et al. Long term high intensity exercise and damage of small joints in rheumatoid arthritis. Ann Rheum Dis 2004; 63:1399-405.

[6].Grossman J, Brahn E (1997) Rheumatoid arthritis: current clinical and research directions. J Womens Health 6(6):627-638.

[7].ghr.nlm.nih.gov/condition/rheumatoid-arthritis accessed on 6/04/2016.

[8].Hakkinen A. Effectiveness and safety of strength training in rheumatoid arthritis. Curr Opin Rheumatol 2004; $16: 132-7$.

[9].Helmick CG, Felson DT, Lawrence RC, Gabriel S, Hirsch R, Kwoh CK, et al. Estimates of the prevalence of arthritis and other rheumatic conditions in the United States: part I. Arthritis Rheum 2008;58:15-25.

[10]. Hakkinen A, Pakarinen A, Hannonen P et al. Effects of prolonged combined strength and endurance training on physical fitness, body composition and serum hormones in women with rheumatoid arthritis and in healthy controls. Clin Exp Rheumatol 2005; 23:505-12.

[11]. Jasvinder., A. Sign., et, al (2015) 2015 American College of Rheumatology, Guideline for the Treatment of Rheumatoid Arthritis.

[12]. J. Bruce Smith (2002) Rheumatoid Arthritis-A Molecular Understanding, Vol 136 No 12.

[13]. Maruotti N, Cantatore FP, Crivellato E, Vacca A, Ribatti D (2007) Macrophages in rheumatoid arthritis. Histol Histopathol 22(5):581-586.

[14]. Ropes MW, Bennet GA, Cobb S, Jacox R, Jessar RA. Revision of diagnostic criteria for rheumatoid arthritis. Bulletin on the Rheumatic Diseases 1958; 9:175-176.

[15]. Scottish Intercollegiate Guidelines Network. Management of Early Rheumatoid Arthritis. SIGN Publication No. 48. Edinburgh: SIGN, 2000. Treatment of rheumatoid arthritis and other inflammatory disorders, unknown author.

[16]. Symmons. A et., al. (2000). The global burden of rheumatoid arthritis in the year 2000.

[17]. Symmons D, et al. The prevalence of rheumatoid arthritis in the United Kingdom; new estimates for a new century. Rheumatology (Oxford) 2002; 41(7):793-800.

[18]. Symmons D, Turner G, Webb R, Aslen P, Barret E, Lunt M et al. The prevalence of rheumatoid arthritis in the United Kingdom; new estimates for a new century. Rheumatology (Oxford) 2002; 41(7):793-800. Royal College of General Practitioners. Office of Populations, Censuses and Surveys. 